\title{
Conditioning history and inhibitory instrumental stimulus control: Independent-groups and within-subjects measures
}

\author{
STANLEY J. WEISS and CHARLES W. SCHINDLER \\ The American University, Washington, D.C.
}

\begin{abstract}
The effects of excitatory conditioning history on establishing inhibitory stimulus control have been investigated in classical conditioning, but not in the free-operant paradigm. The present experiments address this question within the context of discriminated free-operant avoidance in which rats' barpressing postponed shock. When a stimulus with only a history of signaling safety was combined, on a summation test, with a stimulus that maintained avoidance, avoidance rate was reduced, on average, by $60 \%$. In comparison, after a stimulus acquired an excitatory free-operant avoidance history, nonreinforcement alone was not adequate to make it a predictable and effective inhibitor of avoidance on a summation test. These results, consistent with the classical conditioning literature, were produced by both between-group (Experiment 1) and withinsubject (Experiment 2) comparisons. These findings are discussed in terms of (1) Konorski's distinction between "primary" and "secondary" inhibitory stimuli, (2) the Rescorla-Wagner model, (3) the potential contribution of the "reinstatement of fear" to the outcome of summation tests, and (4) their implications for assaying the effectiveness of behavior-modification treatments of phobias.
\end{abstract}

Conditioned excitation is the product of a positive contingency between a stimulus $(\mathbf{S}+)$ and a reinforcer $\left(\mathbf{S}^{\boldsymbol{r}}\right)$, and conditioned inhibition can result from a negative contingency between these events. Although conditioned excitation is readily revealed when the organism is presented with $S+$, conditioned inhibition must be measured indirectly, because, on a simple behavioral level, the conditioned tendency not to make a response cannot be distinguished from the absence of excitation. Pavlov (1927) often used the degree of response reduction to $S+$ on a summation test to measure the inhibitory strength of a nonreinforced stimulus. More recently, Szwejkowska and Konorski (1959) and Reberg and Black (1969) reported response averaging when a reinforced $(\mathrm{S}+)$ and a nonreinforced $(S-)$ stimulus were presented simultaneously. That is, $\mathbf{S}+$ and $\mathbf{S}-$ together elicited fewer responses than S+ but more responses than S-. Rescorla (1969) and Hearst, Beasley, and Farthing (1970) cited the summation (combined cues) test as well as the retardation of acquisition (resistance to reinforcement) assay as relatively straightforward measures that a stimulus controls a tendency opposite to excitation. In the retardation of acquisition procedure, it is assumed that excitatory conditioning to a stimulus with inhibitory properties will have to

This research was supported in part by Grant MH-16853 from the National Institute of Mental Health, awarded to the first author. It was presented at the 1984 meeting of the Eastern Psychological Association in Baltimore. Charies W. Schindler is now at the NIDA Addiction Research Center, P.O. Box 5180, Baltimore, MD 21224. Reprints may be obtained from Stanley J. Weiss, Department of Psychology, The American University, Washington, D.C. 20016. counteract these negative properties before conditioned excitation can be revealed, increasing the number of acquisition trials to reach a set criterion relative to appropriate controls (e.g., see Hammond, 1968; Szwejkowska, 1959; Szwejkowska \& Konorski, 1959).

Although a negative contingency is necessary for the development of a conditioned inhibitor, it is not always sufficient. For example, Konorski (1967) reported that retardation of acquisition occurs only when one tries to transform a stimulus consistently presented without reinforcement ("primary inhibitory stimulus") to an excitatory conditioned stimulus (CS). An excitatory CS subsequently associated with nonreinforcement ("secondary inhibitory stimulus") will recondition faster than a novel stimulus (Konorski \& Szwejkowska, 1950, 1952). Similar effects of conditioning history were reported when a summation test was used as the assay for conditioned inhibition. LoLordo and Rescorla (1966) and Rescorla (1967) found that an extinguished CS did not reduce the fear elicited by a shock-associated CS, but just returned it to the status of a preconditioned stimulus. Coulter and Weiss (1971) and Reberg (1972) even demonstrated that a CS that once controlled conditioned suppression, and subsequently produced conditioned acceleration when it no longer signaled shock, would still act as an excitator of suppression on a summation test. It seems, moreover, that if the CS- is even sufficiently similar to the CS+ to elicit generalized conditioned responses during differential conditioning, that $\mathrm{CS}-$ also fails to act like an inhibitor on a summation test (Thomas \& Basbaum, 1972).

Hendry (1982) recently even revealed in the conditioned suppression paradigm the residual "fear" -eliciting capac- 
ity of two extinguished CSs. Extinction of suppression appeared virtually complete after only 12 trials in her study when assessed by observing response rate to the nonreinforced CSs. However, when two "extinguished" CSs were compounded, significant suppression continued to occur after up to 96 extinction trials-eight times the number required to eliminate suppression to the single CSs.

The interference of an excitatory conditioning history in establishing inhibitory stimulus control has been well established in classical conditioning with the summation and retardation of acquisition tests of inhibition. Rescorla (1969) concluded that "there is no reason to believe that an extinguished CS is a conditioned inhibitor" (p. 88). The present experiments sought to generalize these conclusions by establishing excitatory and inhibitory stimulus control through discrimination training on free-operant baselines. Experiment 1 employed an independent-groups design in which responding was maintained by freeoperant shock avoidance (FOA). Prior to a summation test, in one group a shock-free stimulus had previously maintained avoidance; in the second group, that stimulus had always been safe. In Experiment 2, the same conditioning history question was asked, but a within-subjects design was employed.

\section{EXPERIMENT 1}

\section{Method}

\section{Subjects}

Eighteen 350-450-g male Long-Evans hooded rats received discrimination training in this experiment. They were housed in individual cages with free access to food and water.

\section{Apparatus}

The three similar operant training chambers measured $20 \mathrm{~cm}$ high, $21 \mathrm{~cm}$ long, and $17.5 \mathrm{~cm}$ wide. The front and rear chamber walls were constructed of aluminum. The side walls were white translucent plastic, and the ceiling was clear plastic. The ceiling was vented with 6-mm-diam holes. The chamber floor was composed of 3 -mm-diam stainless steel rods spaced $1.3 \mathrm{~cm}$ apart between centers. A microswitch lever was located on the right side of the front wall, $6.9 \mathrm{~cm}$ above the floor. A feeder trough, which was inoperative throughout Experiment 1, was mounted on the left side of the front wall at floor level. A force equivalent to approximately $15 \mathrm{~g}$ was required to operate the lever.

The 2000-Hz tone stimulus employed in training and testing was presented through a speaker mounted within an enclosure centered $20.6 \mathrm{~cm}$ above the training chamber. The tone intensity was approximately $90 \mathrm{~dB}$ measured at the lever with a sound-level meter, scale $\mathrm{C}$. With the exhaust fan operating, the ambient noise level was approximately $80 \mathrm{~dB}$. The tone stimulus was practically inaudible outside the attenuation chest.

The light stimulus employed in training and testing was generated by two $15-\mathrm{cm}$ showcase $25-\mathrm{W}, 120-\mathrm{V}$ bulbs, each horizontally mounted $10 \mathrm{~cm}$ from the translucent side walls. These two bulbs together produced approximately $130.2 \mathrm{~cd} / \mathrm{m}^{2}$, as measured by a photometer positioned $12.5 \mathrm{~cm}$ from the chamber's side wall.

A shielded 7-W, 120-V bulb operating at $3 \mathrm{~W}$ served as a houselight that was on continuously. Although the illumination it produced was too dim to activate the photometer, it allowed the experimenter to view the subject within the apparatus. The training chamber and its associated stimulus-presentation devices were enclosed within a sound-attenuation chest described elsewhere (Weiss, 1970). Solidstate scheduling equipment was located in a room adjacent to that housing the training chamber. Constant-current shock was generated by a shocker and delivered to the grid floor, manipulandum, and front and rear walls through its associated scrambler.

\section{Procedure}

The aim of the training undertaken was to develop two groups of animals that would reach a baseline condition in which shock postponement (free-operant avoidance) maintained barpressing in $S_{1}$, but freedom from shock (extinction) caused pressing to cease in $S_{2}$. The two groups differed in that for the transfer group $S_{2}$ maintained shock avoidance before it was made safe (shock free), whereas for the control group $\mathrm{S}_{2}$ always signaled a shock-free period. Tone and light were counterbalanced $\left(\mathbf{S}_{1}\right.$ or $\left.\mathbf{S}_{2}\right)$ over avoidance and extinction conditions for the transfer and control groups. The procedure is outlined in Table 1.

Initial training. All animals were initially trained to escape trains of brief (approximately $0.4 \mathrm{sec}$ ) $0.4-0.6$-mA electric shocks. When they were escaping regularly, they were put on a free-operant avoidance schedule in which a response postponed a shock for $25 \mathrm{sec}$ (RS $25 \mathrm{sec}$ ), but once received, the shocks occurred every $2 \mathrm{sec}$ (SS $2 \mathrm{sec}$ ) until a response reinstated the RS interval. As avoidance proficiency improved, the SS interval was increased, in steps, to $5 \mathrm{sec}$ and the session length was extended to $8 \mathrm{~h}$. The transfer group had alternating (2-5-min) periods of $S_{1}$ and $S_{2}$ during this stage of training; the control group received only $S_{1}$. An animal remained in this phase, in which only the RS 25-sec SS 5-sec contingency was in effect, until it was avoiding at least $75 \%$ of the potential RS 25 -sec shocks, that is, receiving fewer than .6 shocks/min, on a regular basis.

Discrimination training. Both groups were next placed on a multiple schedule in which the simultaneous absence of $S_{1}$ and $S_{2}$, that is, tone off and light out $(T+\bar{L})$, signaled a shock-free (extinction) period. For the transfer group, $S_{1}$ and $S_{2}$ were still each associated with avoidance. However, for this group there was a $50 \%$ chance that $T+L$ would be followed by $S_{1}$ or $S_{2}$, with the limitation that neither stimulus was repeated more than three times in succession. $S_{1}$ and $S_{2}$ were always followed by $T+L$. At the start of an avoidance component, the RS 25-sec interval was in effect. The duration of all periods varied unsystematically within the limits of 2-5 $\mathrm{min}$. For the control group, $\mathbf{S}_{\mathbf{1}}$ (tone or light, as appropriate) continued to be associated with avoidance, but $T+\bar{L}$ was shock free. Training continued on this multiple schedule for both groups until, for at least three consecutive sessions, (1) the response rate in tone

Table 1

Procedural Table for Transfer and Control Groups of Experiment 1

\begin{tabular}{|c|c|c|c|c|}
\hline \multirow[b]{2}{*}{ Training } & \multicolumn{2}{|c|}{ Transfer Group } & \multicolumn{2}{|c|}{ Control Group } \\
\hline & FOA & Extinction & FOA & Extinction \\
\hline $\begin{array}{l}\text { Initial } \\
\text { Discrimination } \\
\text { Terminal Baseline }\end{array}$ & $\begin{array}{c}\text { Tone, Light } \\
\text { Tone, Light } \\
\text { Tone* } \\
\text { Stimulu }\end{array}$ & $\begin{array}{c}\quad \overline{\mathrm{T}}+\overline{\mathrm{L}} \\
\text { Light, } \overline{\mathrm{T}}+\overline{\mathrm{L}} \\
\text { nding Test }\end{array}$ & $\begin{array}{l}\text { Tone* } \\
\text { Tone } \\
\text { Tone } \\
\text { Stimu }\end{array}$ & $\begin{array}{c}\overline{\mathrm{T}}+\overline{\mathrm{L}} \\
\text { Light, } \overline{\mathrm{T}}+\overline{\mathrm{L}} \\
\text { ounding Test }\end{array}$ \\
\hline
\end{tabular}

*Training conditions were counterbalanced over tone and light stimuli within groups. 
and/or light was 10 times that emitted in $T+E$ or $T+L$ rate was no more than 1 response/min, and (2) responding usually commenced in tone and/or light before a shock prompt. Shock intensities were modestly increased during this stage of training, if necessary, to maintain avoidance proficiency.

Terminal baseline. Both groups were next introduced to their three-component terminal baseline schedule. Here, one stimulus, $S_{1}$ (tone or light), continued to signal free-operant avoidance and the other stimulus, $S_{2}$ (light or tone), was shock free. The latter stimulus had been associated with avoidance in Phase 2 for the transfer animals, but the control subjects experienced $S_{2}$ for the first time here. $T+[$ continued to be shock free for both groups. Stimuli were sequenced and timed as they had been in Phase 2 for the transfer group, with the exception that the tone or light components associated with extinction were extended to 8-10 min during the initial sessions of this terminal training. Animals were trained until, for at least three consecutive sessions, (1) the $S_{1} / S_{2}$ and $S_{1} / T+\bar{L}$ discrimination ratios were greater than $10: 1,(2)$ shock rate was less than $0.6 / \mathrm{min}$, and (3) avoidance responding commenced prior to a shock prompt in more than $75 \%$ of the avoidance components.

In all phases of training, the animals received 8-h sessions on alternate days. Four animals were eliminated from the study during discrimination training-two because of equipment malfunction or training error, and two because they frequently required a shock prompt after the commencement of an avoidance component before they would start responding.

Testing. After meeting the terminal baseline discrimination and shock-rate criteria, a summation (stimulus compounding) test was administered to each animal. This test commenced after the rat was given a 30-60-min warmup on its terminal baseline multiple schedule. One-minute tone $(\mathrm{T})$, light ( $\mathrm{L})$ and tone-plus-light $(\mathrm{T}+\mathrm{L})$ periods were presented in each of 15 block replications. These stimuli, presented in nonsystematic order over replications, were each separated by $1-$ min $T+\bar{L}$ periods. Shock was disconnected during all test replications. However, to better maintain responding during the test, approximately one-third and two-thirds through the test brief reacquisition periods were introduced. These periods consisted of 2-min presentations of the light and tone components, separated by 1 min of $\bar{T}+\bar{L}$, with the shock reconnected during the $S_{1}$. Care was taken to ensure that each of the test stimuli was equally likely to immediately follow these reacquisition periods.

\section{Results and Discussion}

Immediately prior to testing, the transfer and control groups were on identical terminal baseline schedules. $S_{1}$ (tone or light) was associated with free-operant avoidance (RS $25 \mathrm{sec}$, SS $5 \mathrm{sec}$ ), and $S_{2}$ (light or tone) and $\bar{T}+\bar{L}$ signaled shock-free periods. The transfer animals received an average of 13.6 sessions on this schedule, and the controls received a comparable $16.2[\mathrm{t}(12)=0.57, \mathrm{p}>0.6]$. Baseline behavior on this schedule was indistinguishable over groups in spite of the 14.8 sessions, on average, the transfer group received during the discrimination training phase in which $S_{2}$ was associated with FOA. The control group experienced only FOA-correlated $S_{1}$ and shockfree $T+\bar{L}$ during discrimination training. Sessions required to reach the criteria of the discrimination training phase were also comparable over groups $[\mathrm{t}(12)=1.69$, $\mathrm{p}>.10]$.

Mean rates of the transfer and control groups at the end of discrimination training are given in the left frame of Figure 1. Mean avoidance rates were comparable within (transfer) and between (control vs. transfer) groups. Rate

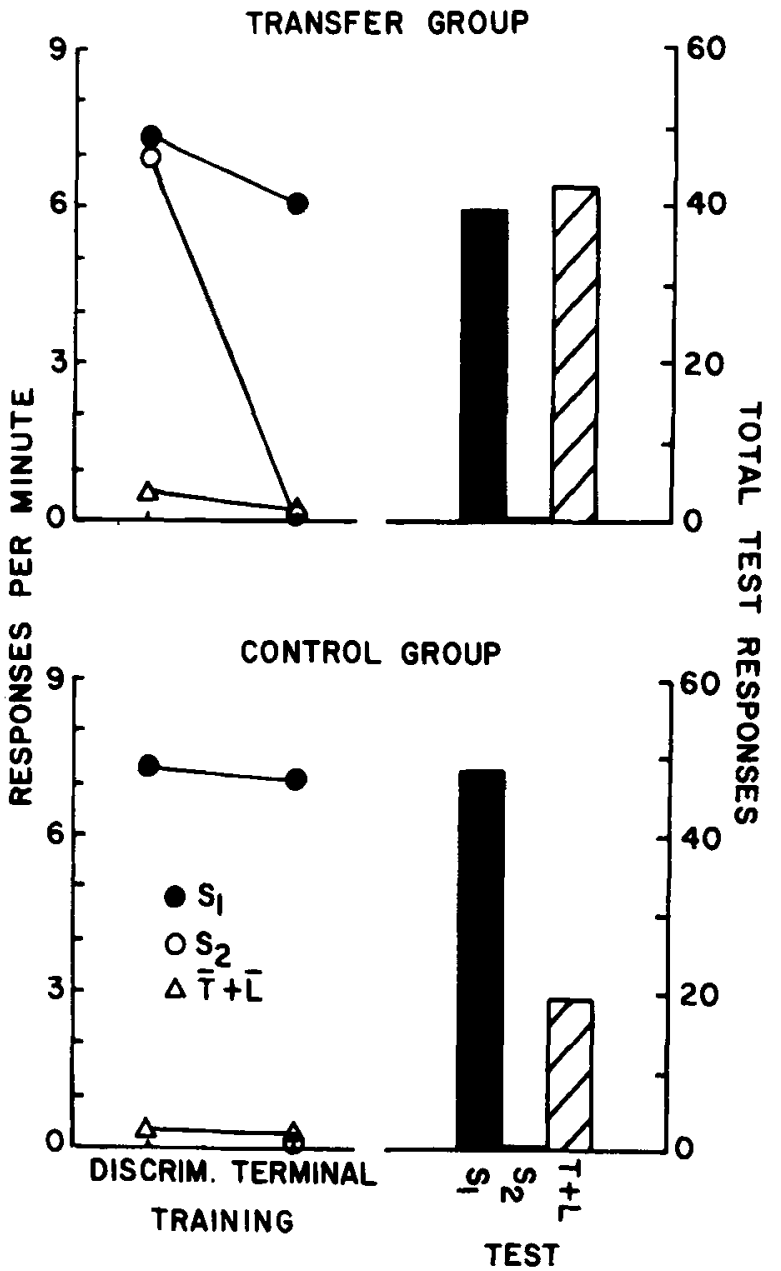

Figure 1. Mean performance of the transfer and control groups of Experiment 1 during discrimination and terminal baseline training (left frames) and on the summation test (right frames). Training data is presented in terms of response rate, and the test results, in terms of total response output to each condition.

in $\bar{T}+\overline{\mathrm{L}}$ was low in both groups, 0.55 responses $/ \mathrm{min}$ for the transfer group and 0.28 responses/min for the control group.

Response rates in $S_{1}$ and $S_{2}$ for both groups during the criterion sessions of terminal baseline training are also given in Figure 1. Over groups, (1) no responses at all were emitted in $S_{2}$ by most animals, (2) average rates in $S_{1}$ were less than 1 response/min apart, and (3) $T+E$ rates were almost identical. Furthermore, shock parameters were similar for transfer and control groups -1.09 and $1.03 \mathrm{~mA}$ received at .34 and .32 shocks/min, respectively.

Responses emitted to each test condition during the stimulus compounding test by the transfer and control groups are presented in the right frames of Figure 1. Between-group comparisons reveal that both groups responded comparably to $S_{1}[t(12)=0.62, .6>p>$ $.5]$, whereas no responses were emitted by subjects of either group in $S_{2}$. However, the transfer group emitted 
twice as many responses in $\mathrm{T}+\mathrm{L}$ as did the control group, 39.4 and 19.5 , respectively $[\mathrm{t}(12)=2.19, \mathrm{p}<.05]$.

Within-group comparisons reveal that, for the transfer group, $S_{1}$, the FOA-associated stimulus, and $\mathrm{T}+\mathrm{L}$ controlled comparable average response outputs, 42.3 and 39.4 test responses, respectively $[t(7)=0.41, p>.6]$. In contrast, for the control group $\mathrm{T}+\mathrm{L}$ controlled only $40.4 \%$ of the response output to $S_{1}[t(5)=2.97, p<$ $.05]$. The effects of $S_{2}$ conditioning history are substantiated by the between- as well as the within-group comparisons.

When the extinction-associated stimulus $\left(\mathrm{S}_{2}\right)$ was compounded with the avoidance-associated stimulus $\left(S_{1}\right)$, avoidance rates were consistently, and significantly, reduced only in the control group, for which $S_{2}$ had no avoidance history. Prior to their summation tests, both groups were behaviorally comparable in their rates to $S_{1}$, $S_{2}$, and $\bar{T}+\bar{L}$ (Figure 1). It is therefore clear that the overall group differences can be attributed to the effects of the $S_{2}$ conditioning history, which distinguished the transfer and control groups. Furthermore, $T+L$ was a novel configuration of the training stimuli for both groups. Thus, whatever unconditioned disruptive powers this configuration might have had should have influenced both groups.

One could argue, nevertheless, for a control with $T+L$ containing a novel stimulus. Unfortunately, this type of control would not be informative, because there is nothing comparable about compounding a discriminative stimulus for FOA with an extensively contacted stimulus, like $S_{2}$ in the present experiment, and compounding it with a novel stimulus. A functional analysis of other conceivable controls for the contribution of disruption or generalization decrement to the response reduction to $\mathrm{T}+\mathrm{L}$ by the control group confronts the same question of comparability. The significant test differences between control and transfer groups of this experiment, systematically replicated in Experiment 2, reveal the power of the manipulated variables, and stand on their merits.

Weiss (1977) did report some results potentially relevant to a concern about the unconditioned disruptive powers of the compound. He gave rats extensive training in which FOA operated in tone, light and $\bar{T}+\bar{L}$. After this nondifferential contact with tone and with light, the avoidance rate maintained in testing was the same to $T+L$ as to tone and to light separately presented. The $\mathrm{T}+\mathrm{L}$ configuration had no unconditioned disruptive powers.

\section{EXPERIMENT 2}

Experiment 1 showed, for the first time, the effect of conditioning history on efforts to produce inhibitory freeoperant stimulus control. An independent-groups design was used. Experiment 2 attempted to strengthen, and add generality to, this finding through a systematic replication that employed a within-subjects design. $S_{1}$ was associated with FOA over all phases. The control exerted by $S_{2}$, on the training baseline and a summation test, was monitored when (1) $S_{2}$ had been associated only with safety (Phase 1), (2) $S_{2}$ as well as $S_{1}$ maintained avoidance (Phase 2), and (3) $S_{2}$ again signaled safety (Phase 3). The distribution of responses to $S_{1}$ and $T+L$ on the summation tests of Phases 1 and 3 can be followed for each subject. This enabled us to appreciate subtle changes in inhibitory control produced by conditioning history. Finally, we have an independent measure of the excitatory properties acquired by $S_{2}$ from the results of the summation test of Phase 2.

\section{Method}

Subjects

The six rats in the control group of Experiment 1 were the subjects of Experiment 2.

\section{Apparatus \\ The apparatus was the same as that used in Experiment 1.}

\section{Procedure}

Phase 1. Phase 1 consisted of the same terminal baseline training received by the control group of Experiment 1. FOA maintained barpressing in $S_{1}$, whereas barpressing ceased in $S_{2}$, which was shock free. $S_{1}$ and $S_{2}$ were followed by tone-off light-out $(T+L)$ shock-free periods. This schedule is completely described in Experiment 1. Baseline and test data of this phase of Experiment 2 came from the control subjects in Experiment 1.

Phase 2. After their stimulus compounding test, the subjects from the control group of Experiment 1 were placed on a schedule in which an FOA contingency (RS $25 \mathrm{sec}$, SS $5 \mathrm{sec}$ ) operated in their former $S_{2}$ as well as in $S_{1}$. (For details of this schedule see the discrimination training phase for the transfer group in Experiment 1.) Phase 2 training continued until comparable avoidance responding was maintained in $S_{1}$ and $S_{2}$ for three consecutive sessions in which these rates were at least 10 times those in $T+\bar{L}$. Then a stimulus compounding test identical to the one they received in Experiment 1 (their Phase 1 training in this experiment) was administered.

Phase 3. After their stimulus compounding test of Phase 2, these rats were returned to their Phase 1 training schedule, in which FOA operated in $S_{1}$ but $S_{2}$ was shock free. When $S_{1}$ rates were 10 times those of $S_{2}$ for 3 consecutive days, these rats received their third, and final, stimulus compounding test.

\section{Results and Discussion}

In their initial and final phases of training (Phases 1 and 3), the subjects run as the control group of Experiment 1 had FOA operating in $S_{1}$, and $S_{2}$ was shock free. In Phase 2, FOA operated in $S_{1}$ and $S_{2}$. Mean training rates in $S_{1}$ were 7.2, 7.1, and 7.1 responses/min in Phases 1 , 2 , and 3, respectively, and mean rates in $S_{2}$ were $0,7.0$, and 0.1 , respectively (Table 2 ).

The summation test results for all three phases are presented in Table 3. (Phase 1 results are, of course, those of the control group in Experiment 1.) A treatments $x$ subjects ANOVA of Phase 1 yielded an $\mathrm{F}(2,10)=18.63$, $\mathrm{p}<.001$ (Lindquist, 1953). In Phase 1, significantly more responses were emitted to $S_{1}$ than to $S_{2}[t(10)=$ $6.06, \mathrm{p}<.01]$ or $\mathrm{T}+\mathrm{L}[\mathrm{t}(10)=3.62, \mathrm{p}<.01]$, and significantly more responses were emitted to $\mathrm{T}+\mathrm{L}$ than to $S_{2}[t(10)=2.45, p<.05]$. As already demonstrated, $\mathrm{S}_{2}$ clearly acted as an inhibitor of avoidance here.

In Phase 2, an ANOVA of the compounding test results yielded an $F(2,10)=27.16, p<.001$. Although responding was comparable in $S_{1}$ and $S_{2}[t(10)=0.63, p>0.5]$, 
Table 2

Responses per Minute During Criterion Training Sessions of Experiment 2

\begin{tabular}{|c|c|c|c|c|c|c|c|c|c|}
\hline \multirow[b]{2}{*}{ Subject } & \multicolumn{3}{|c|}{ Phase 1} & \multicolumn{3}{|c|}{ Phase 2} & \multicolumn{3}{|c|}{ Phase 3} \\
\hline & $\begin{array}{c}S_{1} \\
(F O A)\end{array}$ & $\begin{array}{c}S_{2} \\
\text { (Ext.) }\end{array}$ & $\begin{array}{l}\overline{\mathrm{T}}+\overline{\mathrm{L}} \\
\text { (Ext.) }\end{array}$ & $\begin{array}{c}S_{1} \\
\text { (FOA) }\end{array}$ & $\begin{array}{c}\mathrm{S}_{2} \\
(\mathrm{FOA})\end{array}$ & $\begin{array}{l}\overline{\mathrm{T}}+\overline{\mathrm{L}} \\
\text { (Ext.) }\end{array}$ & $\begin{array}{c}\mathrm{S}_{1} \\
\text { (FOA) }\end{array}$ & $\begin{array}{c}S_{\mathbf{2}} \\
\text { (Ext.) }\end{array}$ & $\begin{array}{c}\overline{\mathrm{T}}+\overline{\mathrm{L}} \\
\text { (Ext.) }\end{array}$ \\
\hline 326 & $9.7^{*}$ & 0 & .3 & 10.5 & 9.4 & .6 & 9.8 & 0 & .1 \\
\hline 333 & $6.1^{*}$ & 0 & .1 & 6.6 & 7.1 & .3 & 6.3 & .2 & .4 \\
\hline 351 & 6.6 & $0^{*}$ & .1 & 7.4 & 6.6 & .3 & 8.0 & .3 & .1 \\
\hline 360 & $6.1^{*}$ & 0 & .3 & 5.7 & 5.7 & .7 & 5.5 & .1 & .4 \\
\hline 366 & 5.2 & $0^{*}$ & .1 & 5.9 & 5.8 & .8 & 6.0 & 0 & 0 \\
\hline 367 & $8.6^{*}$ & .1 & 3 & 6.7 & 7.4 & .5 & 6.8 & .1 & .3 \\
\hline Mean & 7.1 & .02 & .2 & 7.1 & 7.0 & .53 & 7.1 & .12 & .22 \\
\hline
\end{tabular}

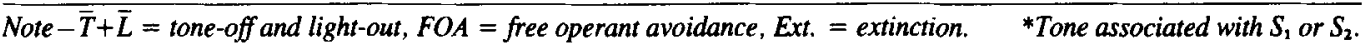

Table 3

Total Responses Emitted to Each Test Condition on Summation Tests of Experiment 2

\begin{tabular}{|c|c|c|c|c|c|c|c|c|c|}
\hline \multirow[b]{2}{*}{ Subject } & \multicolumn{2}{|l|}{ Phase } & 1 & \multicolumn{3}{|c|}{ Phase 2} & \multicolumn{3}{|c|}{ Phase 3} \\
\hline & $\begin{array}{c}S_{\mathrm{l}} \\
\text { (FOA) }\end{array}$ & $\begin{array}{c}S_{2} \\
\text { (Ext.) }\end{array}$ & $\mathrm{T}+\mathrm{L}$ & $\begin{array}{c}S_{t} \\
\text { (FOA) }\end{array}$ & $\begin{array}{c}S_{2} \\
(\mathrm{FOA})\end{array}$ & $T+L$ & $\begin{array}{c}S_{1} \\
(\mathrm{FOA})\end{array}$ & $\begin{array}{c}S_{2} \\
\text { (Ext.) }\end{array}$ & $T+L$ \\
\hline 326 & $83 *$ & 0 & 8 & 101 & 79 & 169 & 104 & 0 & 76 \\
\hline 333 & $45^{*}$ & 0 & 23 & 44 & 41 & 121 & 73 & 2 & 106 \\
\hline 351 & 52 & $0^{*}$ & 29 & 30 & 22 & 148 & 76 & 0 & 140 \\
\hline 360 & $34^{*}$ & 0 & 12 & 32 & 41 & 67 & 49 & 4 & 20 \\
\hline 366 & 47 & $0^{*}$ & 42 & 45 & 28 & 82 & 38 & 0 & 70 \\
\hline 367 & $29^{*}$ & 0 & 3 & 36 & 35 & 102 & 35 & 0 & 41 \\
\hline Mean & 48.3 & 0 & 19.5 & 48 & 41 & 114.8 & 62.5 & 1 & 75.5 \\
\hline
\end{tabular}

significantly more responses were emitted to $\mathrm{T}+\mathrm{L}$ than to $S_{1}[t(10)=6.04, p<.01]$ or $S_{2}[t(10)=6.67, p<$ $.01]$.

Robust additive summation (Weiss, 1972, 1978) was exhibited here, with the magnitude of the effect no smaller than that reported when $S_{2}$ had had no previous inhibitory training (Emurian \& Weiss, 1972). $S_{2}$ clearly acted in an excitatory capacity, with $\mathrm{T}+\mathrm{L}$ controlling approximately 2.5 times the rate to $S_{1}$ or $S_{2}$.

The outcomes of the final stimulus compounding tests are presented in the Phase 3 section of Table 3. Here an ANOVA yielded an $F(2,10)=14.10, p<.005$. Significantly fewer responses were emitted to $S_{2}$ than to $S_{1}$ $[\mathrm{t}(10)=4.10, \mathrm{p}<.01]$ or $\mathrm{T}+\mathrm{L}[\mathrm{t}(10)=4.97, \mathrm{p}<$ $.01]$. However, $S_{2}$ did not act as an inhibitor here. Responding in $S_{1}$ and $\mathrm{T}+\mathrm{L}$ was comparable [ $\mathrm{t}(10)=$ $0.87, p>0.4]$. As in Experiment 1, a currently safe stimulus with an avoidance history did not act like an inhibitor on a summation test.

Responding to $S_{1}$ was comparable in the compounding tests of Phases 1,2 , and $3[\mathrm{~F}(2,10)=3.20, .1>\mathrm{p}>$ $.05]$, whereas that to $\mathrm{T}+\mathrm{L}$ was different over phases $[F(2,10)=18.26, p<.001]$. Significantly more responses were emitted to $\mathrm{T}+\mathrm{L}$ in Phase 2 than in Phase 1 $[\mathrm{t}(10)=6.01, \mathrm{p}<.01]$ or Phase $3[\mathrm{t}(10)=2.48, \mathrm{p}<$ $.05]$, while significantly fewer response were emitted to $T+L$ in Phase 1 than in Phase $3[t(10)=3.5, p<.01]$. This means that (1) the most responses were emitted to $\mathrm{T}+\mathrm{L}$ when it was composed of two avoidance-associated stimuli (Phase 2); (2) the fewest responses were emitted to $\mathrm{T}+\mathrm{L}$ when it was composed of an active avoidance stimulus and one that had always been shock free (Phase 1); and (3) the rate to $\mathrm{T}+\mathrm{L}$ was intermediate to Conditions 1 and 2, above, when it was composed of an active avoidance stimulus and a currently safe, but previously shock-associated, stimulus. Thus, in Experiment 2 the effect of conditioning history on inhibitory control was demonstrated when response outputs to $S_{1}, S_{2}$, and $T+L$ were compared within each phase and when the responses emitted to $\mathrm{T}+\mathrm{L}$ were compared over phases. The agreement between these two comparisons serves as an internal check of the change in the properties of $S_{2}$ over phases. The distribution of responses on the summation tests of Experiment 2 are presented graphically in Figure 2.

\section{GENERAL DISCUSSION}

Konorski's (1967) distinction between the properties of a "primary inhibitory stimulus" and a "secondary inhibitory stimulus" was confirmed by the current experiments. He based his conclusion upon a retardation of acquisition measure in classical appetitive conditioning. Employing instrumental discrimination training with free-operant avoidance (FOA) contingencies, we demonstrated on the summation tests of Experiments 1 and 2 that a currently safe stimulus that previously had controlled avoidance ("secondary inhibitory stimulus"), but no longer maintained avoidance, did not act as an inhibitor. In comparison, when a stimulus with only a history of signaling 


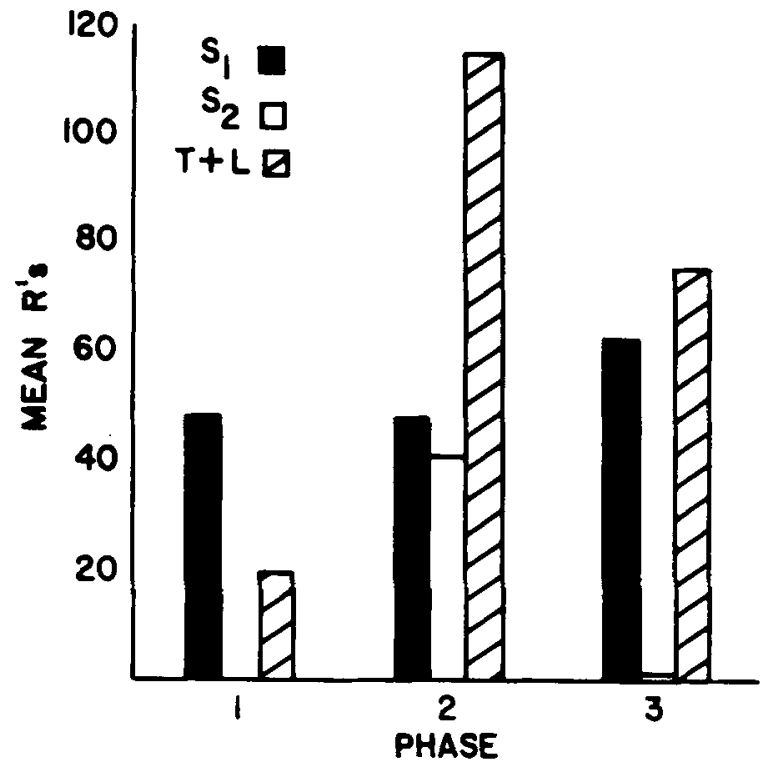

Figure 2. The distribution of responses on the summation tests of Phases 1, 2, and 3 of Experiment 2. Over all phases of training, FOA was effective in $S_{1}$. In Phase $1, S_{2}$ had a history only of signaling safety. In Phase 2, FOA was scheduled in $S_{1}$ and $S_{2}$. Finally, in Phase $3, S_{2}$ again signaled safety, but with the FOA history acquired in Phase 2.

safety ("primary inhibitory stimulus") was combined with a stimulus that maintained avoidance, avoidance was reduced, on average, by $60 \%$.

The need for an indirect measure of inhibition was plainly revealed in the current experiments. In Experiment 1 , immediately prior to the summation test, as well as on the test itself (see Figure 1), there was essentially a total absence of responding to $S_{2}$ (the condition in which FOA was not operating) in both the transfer and control groups. However, the summation test revealed that this nonresponse in $S_{2}$ did not represent the same process in the two groups. Similarly, in Experiment 2, responding (or more accurately the absence of responding) to $S_{2}$ was comparable in training (Table 2) and testing (Table 3 ) in Phases 1 and 3. Nevertheless, $S_{2}$ acted as an inhibitor of avoidance in Phase 1, prior to its avoidance history, but not in Phase 3, after the avoidance history acquired in Phase 2.

Two studies employing conditioned suppression have explicitly investigated the effects of associating a stimulus with safety after it had signaled shock (Coulter \& Weiss, 1971; Reberg, 1972). In neither case did the currently safe stimulus act as an inhibitor. This conditioning history question has not been explicitly posed in the avoidance situation. However, Rescorla (1967) reports some relevant data from an experiment in which Pavlovian fear-conditioning trials were presented while dogs were responding on a free-operant avoidance schedule. Each 30-sec CS terminated with a brief 8-mA shock. After 12 conditioning days, relative to pre-CS rates, avoidance rates declined by half early in the $\mathrm{CS}$ and doubled late in the CS-indicating that the early part of the
CS became an inhibitor of fear (CS-) whereas the latter part became an excitator (CS+). However, repeated presentation of the CS without the US returned the rates both early and late in the CS to baseline. The latter part of the CS did not become inhibitory even though it no longer predicted shock, consistent with previous findings that an extinguished excitatory CS does not become an inhibitor. When the present experiments directly compared the inhibitory properties of extinguished discriminative stimuli for avoidance with those of stimuli that never signaled shock, inhibition was likewise revealed only to the latter stimuli.

The Rescorla-Wagner model is the only theoretical analysis of classical discriminative conditioning that directly confronts the previously cited findings on the effects of conditioning history on the acquisition of inhibitory control (Rescorla \& Wagner, 1972; Wagner \& Rescorla, 1972). According to the model, inhibition is generated only when there is a negative discrepancy between the current associative strength of a stimulus compound and the strength that the ensuing reinforcer will support. That is because the associative strength assumed produced by nonreinforcement is not negative, but zero. Thus, simple nonreinforcement of a CS in isolation will not make that CS inhibitory. Rather, if conditioned inhibition is to be generated, the CS should be nonreinforced in compound with other cues that make the aggregate associative strength of all cues present on that trial positive.

According to the model, to establish conditioned inhibition during $\mathrm{CS}+/ \mathrm{CS}$ - discriminative conditioning, background cues during initial CS- presentations must not be at the zero, or negative, associative strength a prolonged excitatory conditioning history with $\mathrm{CS}+$ would produce. Early in discriminative conditioning, CS+ develops excitation before CS- develops inhibition (Weisman \& Litner, 1969), and during that period some excitatory strength generalizes to background cues (Pavlov, 1927, p. 115). Thus, early in training, conditioned inhibition is generated to a CS- that is nonreinforced in the presence of excitatory background cues. In comparison, after extensive training with $\mathrm{CS}+$, background cues eventually return to zero associative strength and conditioned inhibition would not be generated on a nonreinforced trial. The Rescorla-Wagner model was formulated specifically for the classical conditioning paradigm. However, it might be relevant to the current operant research, for it is widely accepted that a conditioned fear reaction provides the 1963; Rescorla \& Solomon, 1967; Weiss, 1978).

Particular characteristics of the present experiment are especially relevant if one tries to apply the widely accepted Rescorla-Wagner model to the current findings. For instance, in Experiment 1, $S_{\mathbf{2}}$ was introduced shock free to both groups only after extensive discrimination training that had eliminated avoidance, and presumably excitation, in $T+\bar{L}$ (background). This means that the test results cannot be easily explained on the basis of differential background excitation between groups at the time $S_{2}$ was initially introduced shock free. In fact, with excitation to the 
background essentially eliminated, according to the model, $S_{2}$ should not have become a conditioned inhibitor $(\mathrm{CI})$ for either group. It did, however, clearly serve as a $\mathrm{CI}$ for the control group. However, if one assumes that there was still some excitation, not detected by the avoidance baseline, that remained to the background following discrimination training, much as excitation often appears to remain to CSs following extinction (Hendry, 1982), these results could be consistent with the RescorlaWagner model when the "reinstatement-of-fear" phenomenon is considered. According to this interpretation, $S_{2}$ would have acquired inhibitory properties for the transfer and control groups of Experiment 1, with the inhibition counteracted in the former subjects on the summation test.

The postextinction phenomenon Rescorla and Heth (1975) labeled "reinstatement of fear" might be profitably applied in interpreting these summation tests. They found that presentation of shock alone could cause a nolonger-shock-associated CS to again suppress foodmaintained responding. Similarly, Bouton (1984, Experiments 4 and 5) recently reported that fear of a CS that has undergone extinction may be more susceptible to the influence of contextual fear than is fear of a CS that has never been extinguished.

These "reinstatement" findings could mean that the presentation of an extinguished elicitor of fear in the context of a still-effective fear elicitor, as on a summation test, might reinstate the fear once controlled by the former stimulus, or at least interfere with whatever inhibitory properties it has acquired. In the present experiments, the floor effect of an avoidance rate leaves us no independent measure of whether inhibition has been acquired, other than the summation test. Thus, the interference postulated above is entirely an unsubstantiated conjecture. However, in a conditioned emotional response (CER) paradigm acceleration, suggesting inhibition of fear, as well as suppression that signifies excitation of fear, can be measured on the baseline prior to the summation test.

After using a CER procedure, Coulter and Weiss (1971) and Reberg (1972) reported what they considered to be the "residual fear"-eliciting capacity of extinguished CSs. In both cases, they reported an increase in conditioned suppression when they compounded a CS that currently signaled shock with a CS no longer correlated with shock. This increased suppression occurred even though the extinguished CS alone controlled acceleration, a clear indication that it was being attended to, signaled something other than shock, and was probably a conditioned inhibitor of fear on the baseline. This suggests that when "reinstatement" dynamics could be operating, summation tests as measures of inhibition must be viewed cautiously. Be that as it may, the present results do allow us to conclude that once a stimulus has an avoidance history, even extensive extinction in a differential conditioning situation will not create in that stimulus the capacity to reduce fear engendered by other stimuli, as a stimulus that has always signaled safety in such a situation can.
One might insist that the ultimate test of a "fear" treatment's effectiveness would be for the once-feared stimulus to reduce anxiety in a currently feared situation, that is, the once-feared stimulus should act as an inhibitor on a summation test. For example, would a treatment such as systematic desensitization (Wolpe, 1969) make the treated stimulus an inhibitor of fear? We know of no experiments that have measured the effectiveness of systematic desensitization or other behavioral, or nonbehavioral for that matter, treatments of fear with a summation test. Without data from tests such as these, the present free-operant avoidance experiments and the conditioned suppression studies just cited suggest limitations on the ultimate effectiveness of clinical treatments of phobias, since treated phobias might be "reinstated" in anxiety-provoking contexts.

\section{REFERENCES}

ANGER, D. (1963). The role of temporal discriminations in the reinforcement of Sidman avoidance behavior. Journal of the Experimental Analysis of Behavior, 6, 477-506.

Bouron, M. E. (1984). Differential control by context in the inflation and reinstatement paradigms. Journal of Experimental Psychology: Animal Behavior Processes, 10, 56-74.

Coulter, W. R., \& WEISs, S. J. (1971). Suppressive summation controlled by compounding a shock-associated and a shock-extinguished CS. Proceedings of the 79th Annual Convention of the American Psychological Association, 3, 711-712.

EmuRIAN, H. H., \& Weiss, S. J. (1972). Compounding discriminative stimuli controlling free-operant avoidance. Journal of the Experimental Analysis of Behavior, 17, 249-256.

HammOND, L. J. (1968). Retardation of fear acquisition by a previously inhibitory CS. Journal of Comparative \& Physiological Psychology, 66, 756-759.

Hearst, E., Beasley, S., \& Farthing, G. W. (1970). Inhibition and the stimulus control of operant behavior. Journal of the Experimental Analysis of Behavior, 14, 373-409.

HENDRY, J. S. (1982). Summation of undetected excitation following the extinction of the CER. Animal Learning \& Behavior, 10, 476-482.

KONORSKI, J. (1967). Integrative activity of the brain. Chicago: University of Chicago Press.

KonorsKI, J., \& SzWEJKowsKa, G. (1950). Chronic extinction and restoration of conditioned reflexes: I. Extinction against the excitatory background. Acta Biologiae Experimentalis, 15, 155-170.

Konorski, J., \& SzweJKowSKA, G. (1952). Chronic extinction and restoration of condition reflexes: IV. The dependence of the course of extinction and restoration of conditioned reflexes on the "history" of the conditioned stimulus (the principle of the primacy of first training). Acta Biologiae Experimentalis, 16, 95-113.

LINDQUIST, E. F. (1953). Design and analysis of experiments in psychology and education. Boston: Houghton-Mifflin.

LoLordo, V. M., Rescorla, R. A. (1966). Protection of the feareliciting capacity of a stimulus from extinction. Acta Biologiae Experimentalis, 26, 251-258.

Pavlov, I. P. (1927). Conditioned reflexes. Oxford: Oxford University Press.

REBERG, D. (1972). Compound tests for excitation in early acquisition and after prolonged extinction of conditioned suppression. Learning \& Motivation, 3, 246-258.

Reberg, D., \& Black, A. P. (1969). Compound testing of individually conditioned stimuli as an index of excitatory and inhibitory properties. Psychonomic Science, 17, 30-31.

Rescorla, R. A. (1967). Inhibition of delay in Pavlovian fear conditioning. Journal of Comparative and Physiological Psychology, 64, $114-120$. 
Rescorla, R. A. (1969). Pavlovian conditioned inhibition. Psychological Bulletin, 72, 77-94.

REsCoRLA, R. A., \& HETH, D. (1975). Reinstatement of fear to an extinguished conditioned stimulus. Journal of Experimental Psychology: Animal Behavior Processes, 104, 88-96.

Rescorla, R. A., \& Solomon, R. L. (1967). Two-process learning theory: Relationships between Pavlovian conditioning and instrumental learning. Psychological Review, 74, 151-181.

Rescorla, R. A., \& WAGNer, A. R. (1972). A theory of Pavlovian conditioning: Variations in the effectiveness of reinforcement and nonreinforcement. In A. H. Black \& W. F. Prokasy (Eds.), Classical conditioning II: Current research and theory (pp. 64-99). New York: Appleton-Century-Crofts.

SzWEJKOWSKA, G. (1959). The transformation of differentiated inhibitory stimuli into positive conditioned stimuli. Acta Biologiae Experimentalis, 19, 151-169.

SZWEJKoWSKA, G., \& KoNORSKI, J. (1959). The influence of the primary inhibitory stimulus upon the salivary effect of excitatory conditioned stimulus. Acta Biologiae Experimentalis, 19, 162-174.

Thomas, E., \& Basbaum, C. (1972). Excitatory and inhibitory processes in hypothalamic conditioning in cats: Role of the history of the negative stimulus. Journal of Comparative \& Physiological Psychology, 79, 419-424.
Wagner, A. R., \& Rescorla, R. A. (1972). Inhibition in Pavlovian conditioning: Application of a theory. In R. A. Boakes \& M. S. Halliday (Eds.), Inhibition and learning (pp. 301-336). London: Academic Press.

WeISMAN, R. G., \& LitNer, J. S. (1969). The course of Pavlovian excitation and inhibition of fear in rats. Journal of Comparative \& Physiological Psychology, 69, 667-672.

WEISS, S. J. (1970). An effective and economical sound attenuation chamber. Journal of the Experimental Analysis of Behavior, 13, 37-39.

WEISs, S. J. (1972). Stimulus compounding in free-operant and classical conditioning. Psychological Bulletin, 78, 189-208.

WeIss, S. J. (1977). The isolation of stimulus-reinforcer associations established with multiple schedules. Animal Learning \& Behavior, 5, 421-429.

WEISS, S. J. (1978). Discriminated response and incentive processes in operant conditioning: A two-factor model of stimulus control. Journal of the Experimental Analysis of Behavior, 30, 361-381.

Wolpe, J. W. (1969). The practice of behavior therapy. New York: Pergamon Press.

(Manuscript received February 20, 1985; revision accepted for publication August 22, 1985.) 